\title{
THE PARTITIONING OF THE TRUNCUS AND CONUS AND THE FORMATION OF THE MEMBRANOUS PORTION OF THE INTERVENTRICULAR SEPTUM IN THE HUMAN HEART ${ }^{1}$
}

THEODORE C. 'KRAMER

Department of Anatomy, University of Michigan Medical School, Ann Arbor

NINE FIGURES

\section{IN'TRODUCTION}

This paper deals with the partitioning of the human embryonic heart at the region where the ventricles narrow into the arterial cones and the septum membranaceum completes the interventricular septum. This region has been of interest to many workers because of its importance in the development of the pattern of the circulation, and the frequency of its involvement in congenital defects of the heart, but there are still gaps in our knowledge that invite further investigation.

\section{HISTORICAL SUMMARY}

The earliest study of the partitioning of the heart which can be considered of importance by present-day standards is that of His (1886). He published two papers on the development of the heart based on dissections of young embryos from which free-hand wax models (not reconstructions) were made. These models, reproduced commercially by Zeigler of Berlin, show reasonably well the general external changes in cardiac form. The internal changes are suggested to a certain extent but the method was not sufficiently accurate for detailed analysis of the partitioning process.

${ }^{1}$ A dissertation submitted in partial fulfillment of the requirements for the degree of Doctor of Philosophy. 
In 1888 and 1889 Born published papers on a series of hearts from rabbit embryos and parts of two human fetal hearts. The models on which this work was based were made by the wax plate reconstruction method which is commonly known under his name. Our present knowledge of any phase of the detailed morphology of young embryos springs largely from the application of this method of reconstruction, or modifications of it.

One of the early critical studies of the specific region of the human heart with which this paper is concerned was that of Hochstetter (1898). This work, although not published in detail, was the foundation for the more extensive work of Tandler which followed later from the same laboratory.

Using the Born plate method of reconstruction, Tandler made careful studies of human embryonic hearts of younger stages than those covered by Born. His models of the hearts of 5.2-mm., 6.5-mm., 9-mm., and 14.5-mm. embryos are illustrated in his account of the development of the heart published in Bardeleben's Handbuch Der Anatomie des Menschens which began to appear in installments in the early 1900's. Much the same ground was covered in his chapter in Keibel and Mall's Textbook of Human Embryology published in 1912. This work gave us very accurate information on some of the earlier phases of cardiac partitioning but it was not based on a sufficiently closely graded series of embryos to cover the course of events in the more rapidly changing structures. As far as it goes this work has been confirmed by subsequent investigators and must still be used in laying the foundation of any discussion of cardiac partitioning.

- Working at about the same time Mall ('13) reconstructed the heart of an embryo of $11 \mathrm{~mm}$. in connection with his study of the developing muscular architecture of the ventricles. This model shows conditions in the developing septa in accord with Tandler's findings. Moreover, the age of the embryo fits nicely into the Tandler series and also with the stages described in this paper. 
Frazer ('16) made a study, by the wax plate reconstruction method, of the development of the pars membranacea septi in the human heart. His illustrations, however, were free-hand schematizations, which, while they may make for easier presentation, are difficult to compare satisfactorily with recontructions by other workers. Certain phases of his conclusions will be discussed later in this paper, in connection with my own findings.

Waterston ('18) made reconstructions of the hearts of human embryos of $3 \mathrm{~mm}$., $6 \mathrm{~mm}$., $8 \mathrm{~mm}$., $12.5 \mathrm{~mm}$., $16 \mathrm{~mm}$., $20 \mathrm{~mm}$., $30 \mathrm{~mm}$., and of the truncus arteriosus region of a 9 -mm. embryo. The phases of his work of direct interest in connection with the present problem will be dealt with in the body of the paper.

Odger's ('38) paper on "The Development of the Pars Membranacea Septi in the Human Heart" is, also, so directly in the field of this work that discussion of it can best be postponed to be taken up in connection with our own findings.

It is evident from this brief survey that our knowledge of heart development depends on weaving together information which has been derived from a number of different workers, none of whom had available a really extensive series of stages. As is inevitable under such circumstances there are serious gaps and some apparent inconsistencies in the story.

The part of the heart in which the partitioning process is most difficult to interpret is that region in which the atrioventricular cushions, the conus (bulbar) ridges, and the crest of the interventricular septum all converge to a common meeting point in the formation of the septum membranaceum. At this point, moreover, the partition formed in the truncus arteriosus meets the cono-ventricular portion of the septal complex in such a manner that the right ventricular output is routed into the pulmonary artery, and the left ventricular output into the aorta.

In the present paper an attempt is made to rescrutinize and bring together all the heretofore available information on this interesting region of the human embryonic heart and so to 
supplement it that a less fragmentary and more understandable account may be made available.

\section{MATERIALS AND METHOD}

This study was based on the use of the wax plate reconstruction method. Most of the models were made at a magnification of $100 \times$ or $150 \times$. This relatively high magnification was used because it increased the accuracy with which details could be worked out. The plates were made on the platerolling machine described by Huber in his English edition of the Bohm, Davidoff, Histology, pages 55 to 57. Because of the excessive amount of cutting necessitated by the delicate trabeculation of the young ventricles it was not desirable to embed the drawings in the wax plates as is often done when the plates are made by this method.

In constructing the models the plates were stacked, using a line drawn through the centers of the neural tube and the notochord as a guide to the sagittal plane. The dorsal curvature was established by projecting a photograph of the entire embryo to the scale to be used in the reconstruction. In the cases in which such photographs had not been made before the embryo was sectioned the photograph of another embryo of the same length was substituted. By bending a brass rod to fit the back curvature at the level of the body being reconstructed and fixing this rod in the model base, a guide was afforded for determining, by measurements, the proper dorsoventral position for each plate as it was stacked.

The models have been made dissectable at several levels so that internal structures can be observed. The proximal portions of the main vessels entering and leaving the heart were usually included.

The series used for the reconstructions were selected to dovetail into the series reconstructed by previous workers. After a study of the younger embryos of the University of Michigan Collection the heart of one of this group was selected for reconstruction (E. H. 35). To Doctors Streeter and Corner 
I am indebted for the loan of three other series from the extensive collection of the Carnegie Institute of Embryology.

The embryos from which reconstructions of the hearts were made for this study are listed in the following table:

$\begin{array}{llr}\text { EMB. No. } & \text { COLLECTION } & \text { C. R. LENGTH } \\ \text { E. H. } 35 & \text { U. of M. } & 8.8 \mathrm{~mm} . \\ & & \\ 6521 & \text { Carnegie } & 12.0 \mathrm{~mm} . \\ & & \\ 841 & \text { Carnegie } & 13.0 \mathrm{~mm} . \\ 5537 & & 18.0 \mathrm{~mm} .\end{array}$

REMARKS

Entire heart, aortic arches and duets of Cuvier modeled. Endocardial cushions "inlayed" in white wax.

Truncus and top of ventricles only modeled. Endocardial cushion tissue in white wax "inlay."

Entire heart and main vessels modeled.

Entire heart and main vessels modeled.

Embryo 841 of the Carnegie Collection was listed in their records as $15 \mathrm{~mm}$. in crown-rump length. Only the body of this embryo was available in this series, the head having been used for other purposes. From a count of the sections in this series we have estimated the length of this embryo in the fixed condition as being about $13 \mathrm{~mm}$. This undoubtedly means that the Carnegie measurement of $15 \mathrm{~mm}$. was made before the full shrinkage effect of fixation had occurred. This amount of shrinkage during preparation for sectioning is not at all unusual (Patten and Philpott, '21). This interpretation, moreover, fits well with the fact that the model of this heart is smaller than would have been expected from its degree of development in comparison with the other models of the series reconstructed to the same scale. In spite of the disadvantages due to its shrinkage, this series was selected for study because of the particularly valuable developmental phase exhibited by the heart.

\section{THE PARTITIONING OF THE AORTIC TRUNK AND THE VENTRICLE AS SHOWN BY RECONSTRUCTIONS}

The ventral views of the embryonic hearts shown in figure 1 were assembled from various sources and redrawn in com- 
parable orientation and magnification to show the early changes in external configuration and the establishing of the primary regional divisions of the heart. The relatively straight condition of the young tubular heart is short-lived. An elongation of the cardiac tube, which is much more rapid than the enlargement of the pericardial part of the coelom in which it lies, causes the heart to bend first in a rather U-shaped

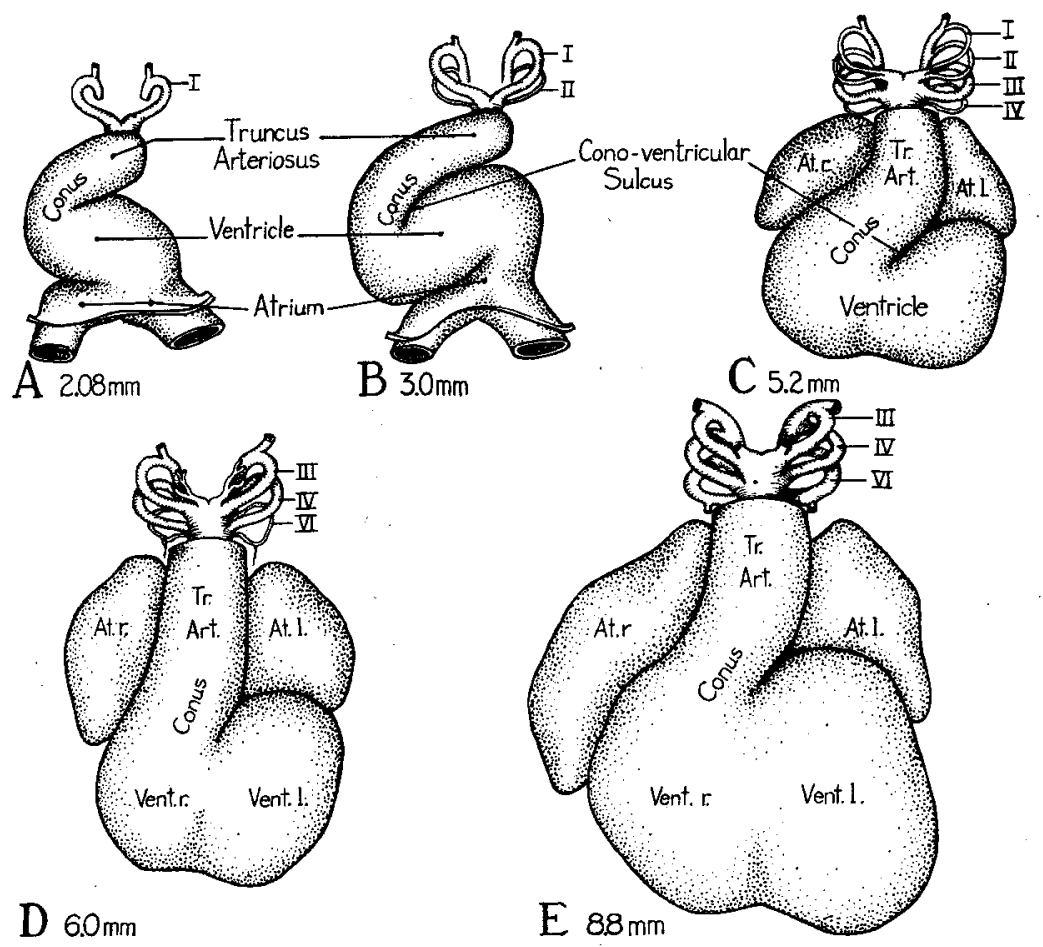

Fig. 1 Ventral views of reconstructions of the hearts of young embryos showing the shift in the position of the truneus toward the mid-line and the reduction of the cono-ventricular suleus. Slight modifications in the redrawing have been made in order to bring the various models into comparable orientation.
A 2.08-mm. embryo $\times 42$ (Modified from Davis, '27, fig. 23).
B 3-mm. embryo $\times 42$ (Modified from Tandler, '12, fig. 374).
C 5.2-mm. embryo $\times 42$ (Modified from Tandler, '12, fig. 378).
D $6.0-\mathrm{mm}$. embryo $\times 21$ (Modified from Waterston, '18, fig. 2).
E 8.8-mm. embryo $\times 21$ (Original figure from reconstruction of EH. 35, Uni- versity of Michigan Coll.). 
fashion to the right (fig. 1, A), and shortly thereafter into a compound S-shaped curve (fig. 1, B). By this time it is possible to recognize the major cardiac regions, although the lines of demarcation between them are still vague. It will be most convenient to consider these regions in a sequence corresponding to the direction of the flow of blood.

The atrial region can be recognized as the transversely dilated portion of the cardiac tube into which the great veins converge. This part of the heart remains dorsally located, being anchored to the body wall by a persistent portion of the dorsal mesocardium and the entering veins. The ventricular part of the cardiac tube, having early lost its dorsal mesocardium, is free to bend laterally and then ventrally. There is at this stage only a poorly marked constriction between the ventricle and the atrium. Cephalically there is a gradual transition from the ventricle to the conus arteriosus communis, or more briefly "the conus." As its name implies, the conus is the somewhat conically shaped part of the heart which joins the ventricle with the truncus arteriosus. The terms "bulbus cordis" and "bulbo-conus arteriosus" are not infrequently applied to the cardiac region here designated as the "conus." Because there is a transitory (aortic) "bulb" at the distal end of the young truncus arteriosus where it turns abruptly dorsad to give off the aortic arches, it seems less confusing to avoid the use of "bulbus" (cordis) in connection with a neighboring structure. The term "bulbo-conus" is at once cumbersome and confusing in that the term is inapplicable to mammalian embryos after the transitory aortic bulb has disappeared. Moreover both these terms have connotations in comparative anatomy which are not readily transferable to primate ontogeny. The term conus is aptly descriptive of conditions in the embryo and furthermore by its division gives rise to that part of the right ventricle commonly known in adult anatomy as the conus pulmonalis, and to the more modified corresponding portion of the left ventricular outlet into the aorta. As the terms are here employed the transition from conus to truncus arteriosus is arbitrarily regarded as taking 
place at the level where the aortic and pulmonary valves are formed. At this early stage the conus grades into the truncus without any definite line of demarcation.

In 5-mm. embryos (fig. 1, C) the regional divisions of the heart have become more definitely delimited. The ventricular loop has been carried into a position caudal and ventral to the atrium. There is a well marked external notch clearly indicating the location at which the interventricular septum is making its appearance internally. The transition from the conus to the truncus is still gradual, although relatively more abrupt than in earlier stages. Very striking is the deep groove at this stage between the conus and that part of the primary common ventricle which is destined to become the left ventricular chamber. Later we shall have occasion to consider more carefully the internal flange arising opposite this groove.

In embryos of $6 \mathrm{~mm}$. (fig. 1, D) and 8 to $9 \mathrm{~mm}$. (fig. $1, \mathrm{E}$ ) a marked growth of the auricular appendages of the atrium is evident. These extensions from the common atrial chamber swing ventrally, lying close against either side of the truncus arteriosus. The atrioventricular groove marking the line of demarcation between atrium and ventricle is by this time clearly defined. The interventricular sulcus has become much deeper, while in contrast the sulcus between the left ventricle and the conus is less extensive than in the younger stages. The changing position of the ventricle and differential growth in the region of transition from ventricle to truncus have combined to shift the conus from the extreme right (fig. 1, B) toward the mid-line (cf. fig. 1, C-E). This shift is of great importance in bringing the partitions in the truncus arteriosus, and in the conus, into line with the interventricular septum.

Accompanying these changes in the external form of the heart, correlated changes have been occurring internally. At the stage shown in figure $1, \mathrm{~A}$, the paired endocardial primordia characteristic of younger embryos have united throughout the ventricular region to form a single endocardial tube. The fusion is pretty well completed also in the atrial region but has not yet extended sufficiently far caudad 
to establish the sinus venosus. In general the endocardial tube follows the configuration of the outer (epi-myocardial) portion of the heart. In very early stages the material between the endocardial and myocardial layers is almost acellular. For this reason it was called by Davis ('27) "cardiac jelly." As development proceeds an increasing. number of mesenchymal cells invade the "cardiac jelly" and start to differentiate into a primitive type of embryonic connective tissue. Because of its tendency to occur in local concentrations this tissue has been called "endocardial cushion tissue." It tends to appear most abundantly where valves and parts of the septal complex are arising.

In embryos of about $5-6 \mathrm{~mm}$. fusion of the paired primordia has extended through the entire length of the cardiac tube, and a definite sinus venosus has been formed where the great veins become confluent as they enter the heart. When first established, the sinus venosus is situated medially on the dorso-caudal side of the atrium, and communicates with it by an oval opening. By the end of the first month of development a thickening appears dorso-cephalically in the wall of the atrium, in its sagittal plane. This is the beginning of the interatrial septum primum. Almost as soon as this first part of the interatrial septal complex is definitely formed the sinus venosus shifts to the right from its primarily median position. At the same time its originally oval orifice becomes slit-shaped, and its margins become thickened and project into the right atrial lumen as the valvulae venosae (Patten, '38).

About this time, also, two sub-endothelial thickenings are becoming evident in the narrowed part of the cardiac tube between the atrium and the ventricle. One of these is dorsally located, and the other lies directly opposite it in the ventral wall. These are the so-called dorsal and ventral endocardial cushions of the atrioventricular canal. They can be designated more briefly as the dorsal, and ventral, A.-V. cushions. Meanwhile, at the caudal border of the ventricular loop, a thickening is becoming evident which presages the formation of the interventricular septum. 
By this time, also, there is a concentration of the endocardial cushion tissue into two longitudinal ridges extending in a clockwise spiral path from the cephalic end of the truncus arteriosus, through the conus, to the ventricle. Although these ridges are by no means equally well developed at all levels some endocardial cushion tissue is present throughout the length of the truncus and the conus. It was undoubtedly the unequal development at different levels which Tandler was emphasizing in describing "proximal and distal bulbar ridges" as separate structures. Probably it was the continuity of the endocardial cushion tissue which led Waterson to say that he was unable to find the discontinuity described by Tandler. The present work would seem to indicate the correctness of both observers and to show that the apparent discrepancy is merely a matter of what phase of the conditions each writer chose to emphasize. There seem to be quite definitely three levels in which the ridge system of the truncus and conus of young embryos are best developed. These three regions, as seen in the reconstruction of an 8.8-mm. embryo, are: (1) in the ventral aortic roots at the level where the fourth and sixth arches are being separated (fig. 2, A) ; (2) in the truncus arteriosus, at the level where the aortic and pulmonary valves are destined to be formed (fig. 2, C) ; and

Fig. 2 Photomicrographs $(\times 65)$ of different levels of the truncus and conus of an 8.8-mm. embryo (U. of M. Coll. E.H. 35).

A At the level of the septum aorto-pulmonale between aortic arches 4 and 6 .

B Truncus, between septum aorto-pulmonale and level of primordia of semilunar valves.

C Through the level at which the semilunar valves are formed.

D Through the conus immediately below the level of the valves.

$E$ Through the conus ridges near the transition from ventricle to conus.

\section{KEY TO ABBREVIATIONS}

Ao.V, Ventral aorta.

ARCH 6, Aortic arch 6.

D.-d.C.R., Dextro-dorsal conus ridge.

D.I.V.S., Dorsal interealated valve swelling.

P.C., Pericardial cavity.

Sept.Ao.-Pul., Septum aorto-pulmonale.
S.-v.C.R., Sinistro-ventral conus ridge. S.-v.T.R., Sinistro-ventral truncus ridge. Tr.Art., Truneus arteriosus.

V.A.-v.Cu., Ventral atrioventricular canal cushion.

V.I.V.S., Ventral intercalated valve swelling. 

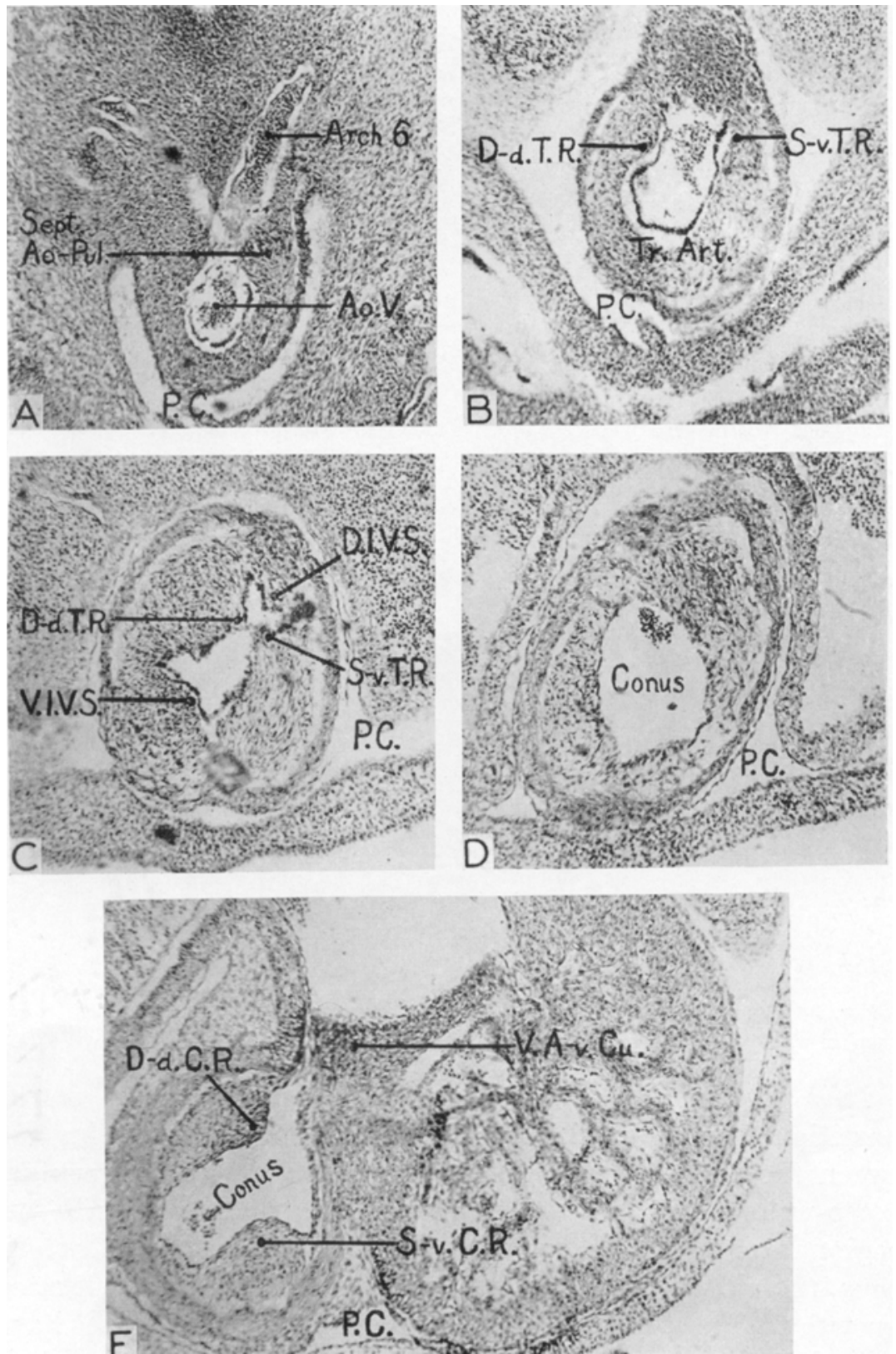

Figure 2 
(3) in the conus, definitely on the ventricular side of the location at which the semilunar valves appear (fig. 2, $\mathrm{E}$ ). Although, as indicated above, there is some endocardial cushion tissue present at all levels (fig. 2, B and D), there is at this stage a definite discontinuity of the ridges. The absence of ridges immediately caudal to the valves is particularly striking (fig. 2, D).

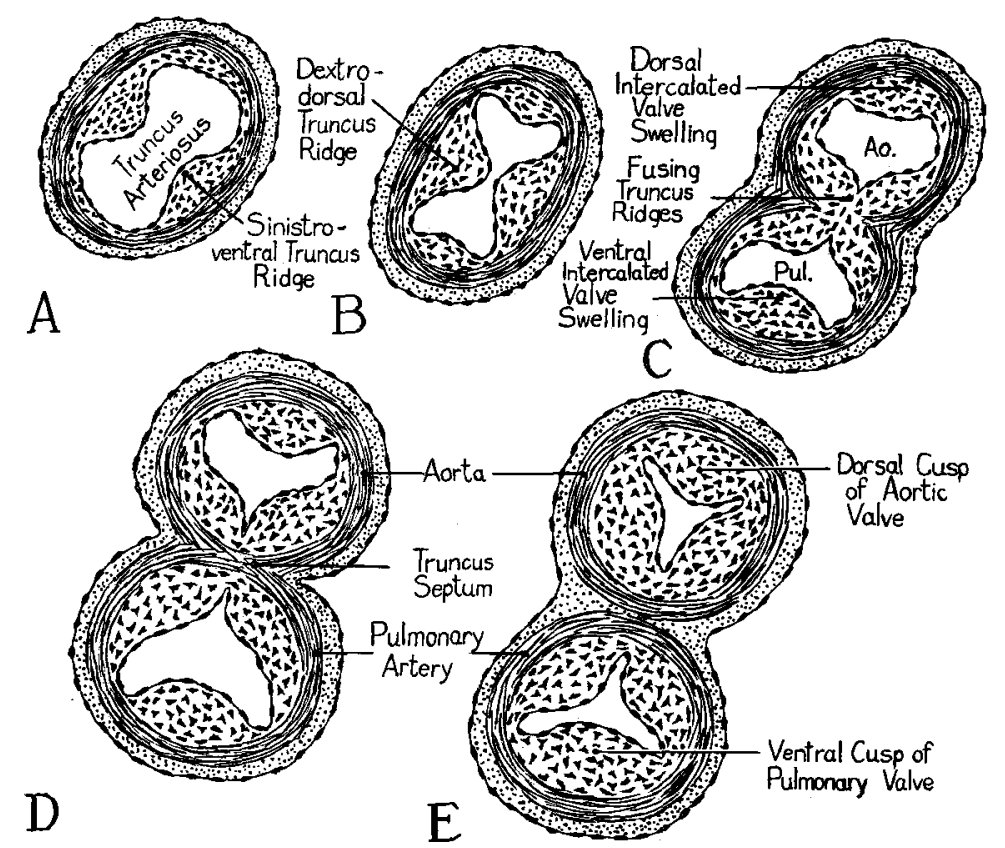

Fig. 3 Schematic diagrams to illustrate the origin of the semilunar valve primordia.

It is proposed in this study to designate that part of the partition formed by the growth of the ridges appearing between the fourth and the sixth aortic arches as the septum aorto-pulmonale, as suggested by Tandler. In line with the regional distinctions here used for conus and truneus arteriosus, the elevations at the second of the levels of accelerated growth will be called the truncus ridges. After the ridges have united to divide the truncus lumen into an aortic and a pulmonary portion the term truncus septum will be used (fig. 3). 
What are here called truncus ridges would, as nearly as I can determine, be the part of the complex which Tandler called the distal bulbar ridges ("Wulste"). The ridges of endocardial cushion tissue in that part of the ventricle which is narrowing as it approaches the outlet into the truncus, will here be called conus ridges, or after their fusion, the conus septum. This undoubtedly is the part of the complex to which Tandler applied the term "proximal bulbar ridges."

It has seemed necessary thus to analyze, and to have terms for the accurate designation of, the different regions in which accelerated growth is occurring. This rather cumbersome terminology should not lead to overlooking the facts that all these regions grade insensibly one into the other, and that ultimately these regions of locally accelerated growth are destined to coalesce into a continuous septal system. This septal system divides the truncus arteriosus into aorta and pulmonary arteries, and at the same time extends into the conus level of the ventricle. There the conus part of the complex meets both the interventricular septum and certain local enlargements of the $A . V$. canal cushions to complete the partitioning of the ventricles in such a manner that the Ieft ventricle discharges into the aorta, and the right into the pulmonary arteries.

At the level where the semilunar valves are formed there are some structural details which should receive attention before we pass on to the consideration of the conus region where the final steps in the ventriculo-cono-truncus partitioning occur. At the level of the developing valves two smaller elevations arise between the main truncus ridges. These elevations are relatively local in cephalocaudal extent and are destined to take part in the formation of the pulmonary and aortic valves, rather than to play any role in the division of the truncus channel. They have been rather unsatisfactorily designated by various workers, either by numbers, or by letters. It would seem desirable to give them a descriptive name such as intercalated valve swellings. The term is admittedly overlong, but it does suggest the position in which 
the structures in question arise between the main truncus ridges, and designating them as swellings rather than as ridges, suggests their more local character. Their positional relations when they first arise are shown in the schematic diagrams of figure 3 . The way in which these two masses of endocardial cushion tissue become moulded, respectively, into the primordium of the dorsal cusp of the aortic valve, and the

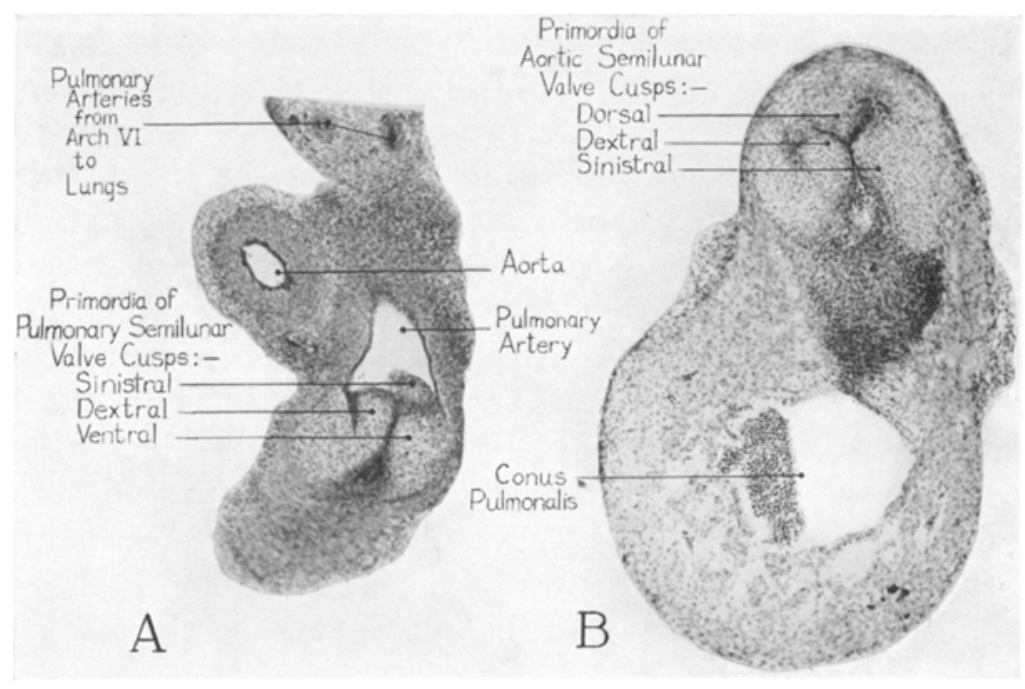

Fig. 4 Photomicrographs $(X 50)$ of sections of a 13-mm. human embryo through the truncus arteriosus at semilunar valve levels.

A Pulmonary valves, eut diagonally because of the sharp bend at this point in the truncus arteriosus.

B The aortic valves, from a slightly more caudal level in the same series where the plane of sectioning euts the outlet more nearly transversely.

primordium of the ventral cusp of the pulmonary valve is indicated in figure 3, D-E. Figure 3 shows also the expansion of the margins of the fusing truncus ridges to form the right and left cusps of the aortic and the pulmonary semilunar valves. Figure 4 shows photomicrographs of sections through the developing valves in a $13-\mathrm{mm}$. embryo. The plane of cutting is such that the aortic and pulmonary valves appear in different sections. The pulmonary valve lies farther cephalad 
in the series and the plane of sectioning passes through it diagonally, so that the limited longitudinal extent of the valve primordia is well shown (fig. 4, A). The aortic valve lies farther caudad and is cut more nearly transversely, so that the relations of the three cusps to each other are well shown (fig. 4, B, and ef. fig. 3, C, D).

In later stages of development there is a further rotation of the heart, so that the relative positions of the aortic and pulmonary outlets are changed from the embryonic conditions depicted in figure 3. This, unfortunately, has resulted in two

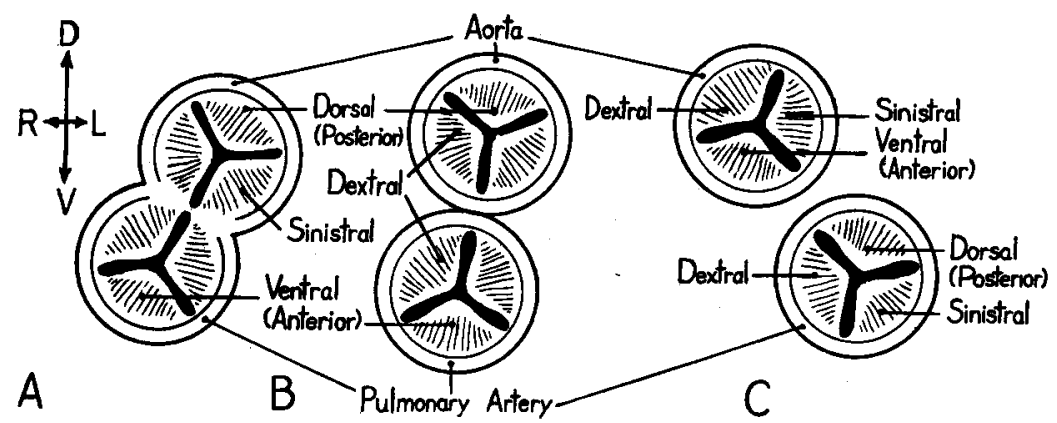

Fig. 5 Schematic diagrams to illustrate the positional relations of the cusps of the aortic and pulmonary semilunar valves. (Modified from figure 534 in Buchanan's Manual of Anatomy, '27.)

A Shows the embryonic positional relations (cf. fig. 3, E).

$B$ Shows an intermediate rotational change toward

$\mathrm{C}$ the adult condition.

sets of names coming into use for the leaflets of the semilunar valves. The BNA designates the cusps on the basis of their position when the heart, removed from the body, is so held that the septal system is the axis of right-left orientation. On this basis the aortic leaflets are dorsal (posterior), right, and left; and the pulmonary leaflets are ventral (anterior), right, and left as in the fetal heart (cf. fig. 3, E and fig. 5, A). The INA terminology is based on the position of the valve cusps as seen in sections of the adult thorax with the heart in situ. On this basis (fig. 5, C) the aortic cusps are right, left, and ventral (anterior), and the pulmonary leaflets are right, left, and dorsal (posterior). 
While the semilunar valves have thus been taking shape, the septum aorto-pulmonale and the growing truncus ridges have coalesced to divide the truncus into the aorta and the pulmonary artery. The manner in which this part of the partitioning process is accomplished is already so well known that it need not concern us further in this paper. With the aortic and pulmonary outlets established in nearly their adult relationships, and their valves clearly differentiated, we can now confine our attention to conditions on the ventricular side of the developing semilunar valves.

The most elusive phases of heart development are those changes which bring the partitioning of the truncus above the semilunar valves into line with the partitioning of the ventricles below the valves. Sir Arthur Keith clearly recognized the importance of this region of the developing heart. His study of an extensive series of anomalous human hearts led him to compare the heart of a human embryo of 3 weeks with the heart of a shark. He published (Keith, '09, fig. 10) two very interesting diagrams indicating the part of the human embryonic heart which he believed to be homologous with the bulbus cordis of the Elasmobranch heart. This theory he used to explain, "a great number of abnormal conditions hitherto inexplicable" (loc. cit. p. 363). In spite of the incompleteness of the morphological evidence on which his conclusions were based, these particular diagrams of his have been reproduced in many textbooks of embryology and many papers on congenital cardiac defects. They certainly embody a very intriguing portrayal of the supposed ontogenetic recapitulation of a remote phylogenetic phase of heart structure, but it has been difficult for me to satisfy myself that I could see in my own reconstructions the landmarks that these diagrams capitalize.

There is one relationship suggested by Keith's diagrams which, regardless of what one may feel as to its possible phylogenetic implications, seems of considerable importance in connection with the partitioning of the conus. This is the position of the extensive flange found internally at the cono- 
ventricular sulcus. The location of this flange makes it necessary for the blood from the left ventricle to negotiate a sharp reverse turn through the interventricular foramen into the right ventricle, before it can leave the heart by way of the truncus (fig. 6, A). It is quite possible that under the static conditions depicted by a model, the sharpness of this turn in the blood channel is exaggerated. In a beating heart it may well be less abrupt. Certainly in observing the living chick heart the turns around which blood currents are driven can be seen to change markedly in different phases of contraction

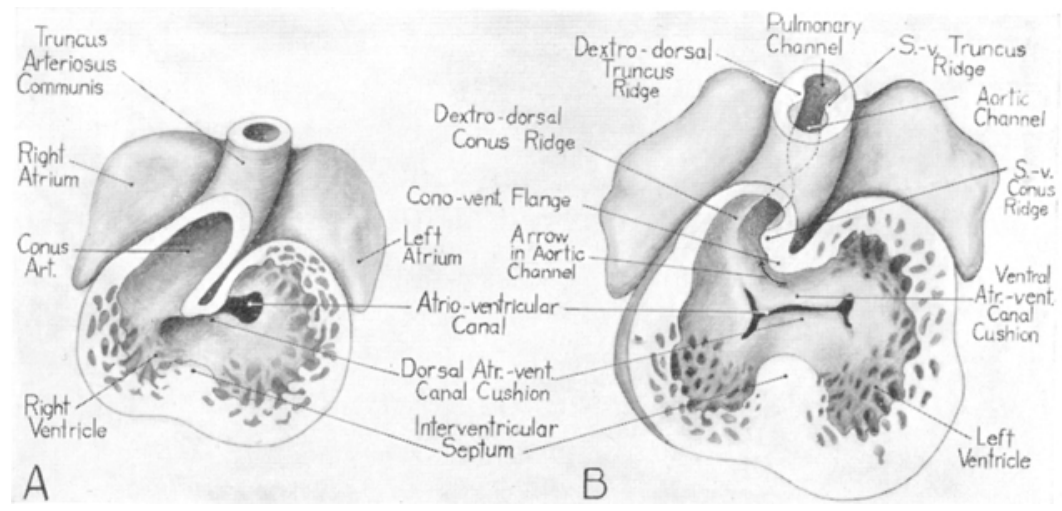

Fig. 6 Semischematic drawings to show the early relations of the conus and ventricle and early stages in the partitioning processes leading toward the establishment of the aortic and pulmonary outlets.

A Heart of an embryo about 4-5 mm. based in part on figure 532 in Buchanan's Manual of Anatomy ('27).

B From a reconstruction of the heart of an $8.8-\mathrm{mm}$. embryo (U. of M. Coll. EH. 35).

(Patten and Kramer, '33). Nevertheless, with all due allowances made for such possible differences between living and fixed hearts, this flange certainly lies across the most direct route for the outlet which must eventually be established from the left ventricle into the aortic part of the truncus. It becomes, therefore, a matter of some theoretical interest whether this flange is reduced entirely by differential growth in its vicinity, or whether there may be some actual resorption of 
its tissues. Keith's diagrams would lead one to think that resorption was the main factor. With this interpretation I would be inclined to disagree, although admittedly this sort of problem is exceedingly difficult to answer with any certainty. The changing relations of the flange with reference to a landmark such as the atrial opening into the ventricle do, perhaps, suggest that there may be some resorption (cf. figs. 6, $A$ and $B$ ). But when one considers also the rapidly increasing size of the ventricles and the atria, and their radical changes in shape and position, it seems inescapable that differential growth is an exceedingly important factor, probably the main factor, in the reduction of the flange. Figure 1, B-D shows how the ventricular loop shifts from the right side to a more median and ventral position, and also how in this same shift the cono-ventricular sulcus comes to lie nearer the sagittal plane. Coincidently, the cephalic end of the cono-ventricular sulcus opens out, and the medial shoulder of the left auricular appendage crowds into it (fig. 1, D and E). The shoulder of the left ventricle also appears to have moved more caudad, thereby helping to lessen the depth of the cono-ventricular sulcus. Along with these changes the internal flange is reshaped into a broad thickened mass of tissue, so located that it no longer interferes with the establishing of a fairly direct path from the left ventricle, through the conus, into the aortic outlet in the truncus (fig. $6, \mathrm{~B}$ ). It seems pertinent to emphasize that the changes thus accomplished do not accord with the simple resorption or retraction process depicted in Keith's figures.

The mesial shift of the conus and the reduction of the cono-ventricular flange, together with the coincident shortening, widening, and straightening of the exit from the ventricles, all combine in paving the way for the final steps in the partitioning process. The septum in the truncus and the conus ridges are now beginning to approach alignment with the interventricular septum (ef. fig. 6, A and B). There remains only the final closure in the region where the conus springs from the ventricle. This is accomplished by the merging of 
plastic endocardial cushion tissue masses derived from the conus ridges, the crest of the interventricular septum, and tubercles which develop from the endocardial cushions of the atrioventricular canal.

Before discussing the final steps in the closure of the conoventricular septal system it is desirable to add certain details to what has already been said about the structures involved.

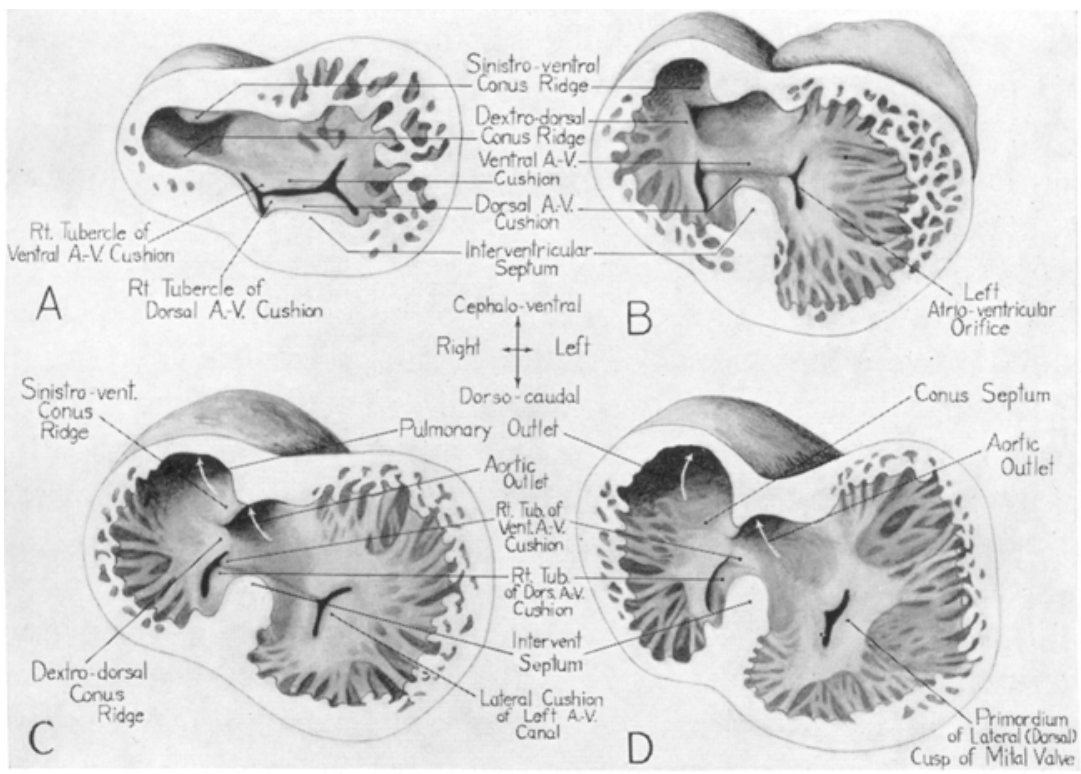

Fig. 7 Drawings of ventral views of reconstructions of hearts of human em. bryos at various stages to show the changes in the conus and ventricles which lead to their partitioning and to the formation of the membranous portion of the interventricular septum.

A 8.8-mm. embryo (U. of M. Coll. EH. 35). .

B 11-mm. embryo (Modified from Mall, '13, fig. 11).

C 13-mm. embryo (Carnegie Emb. Coll., no. 841).

D 14.5-mm. embryo (Modified from Tandler, in Keibel and Mall, '12, fig. 386).

After they first become recognizable, at about the 4-mm. stage, the dorsal and ventral atrioventricular canal cushion masses rapidly increase in thickness and width, until by the 8- to $9-\mathrm{mm}$. stage they project well into the atrio-ventricular canal (figs. 6, $\mathrm{B}$, and $7, \mathrm{~A}$ ). They are quite broad, and each cushion exhibits 
a raised area at each of its lateral borders. These local elevations are the so-called right and left tubercles of the dorsal and ventral endocardial cushions. The tubercles remain conspicuous even after the main part of the cushion masses become apposed to each other, and then fuse, dividing the common atrioventricular channel into a right and a left channel (fig. 7, A and B). The orifices of these channels are at this stage more or less slit-like. Eventually they become the atrioventricular ostia, guarded on the right by the tricuspid valves, and on the left by the mitral valves. For a short time after the fusion of the dorsal and ventral A.-V. canal cushions has taken place, there remains a groove marking the point at which they originally made contact with each other. This groove, although it ultimately disappears entirely, is for a time a valuable landmark indicating the origin of structures which have otherwise lost their identity by fusing. When heart models are opened so that one can look up from below toward the ventricular inlets and outlets, either end of the groove is marked by the notch appearing on the mesial border of each atrioventricular canal (fig. 7, B and C). When the lateral wall of a heart model is removed to give a side view of the septal complex, one looks along this groove, from one ventricle to the other. It is situated in the atrioventricular canal partition, which at this stage forms what might be called the roof of the interventricular foramen (fig. 8, B).

What is called the interventricular septum in the embryo is essentially a muscular ridge which is the primordium of the muscular part of the septum of the adult heart, in distinction to the interventricular septum membranaceum. For brevity, in the following description the term interventricular septum will be used for the primary muscular portion of the septum. When it is wished to refer to the fibrous portion of the adult interventricular septum, the term septum membranaceum will be employed. It is necessary to be thus explicit, for the adult interventricular septum is a composite structure and formed only in part from the embryonic "interventricular septum." Moreover, the embryonic septum as such, is not destined to 
close. The original interventricular foramen above the broad primary muscular septum is remoulded into the aortic cone, and the final steps in the partitioning of the ventricle and conus take place where this foramen opens out into the right ventricle, definitely to the right of the plane of the primary interventricular septum. It is necessary clearly to understand these relations to appreciate the important role played by the right tubereles of the A.- V. canal cushions in the formation of the septum membranaceum.

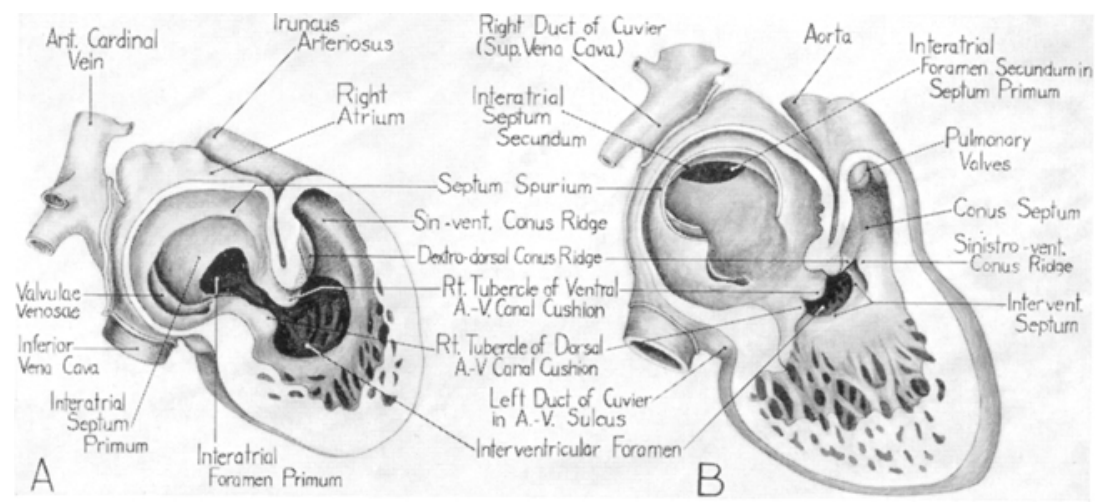

Fig. 8 Semischematic drawings to show the relations of the various parts of the septal system in lateral aspect (Collaboration with Bradley M. Patten).

A Based on reconstructions of the hearts of embryos $8-10 \mathrm{~mm}$.

$B$ Based on reconstructions of the hearts of embryos $12-14 \mathrm{~mm}$.

The tubercles grow very rapidly and extend toward the conus septum and the right side of the gap above the interventricular septum. The right tubercle of the ventral cushion becomes somewhat conical in shape with its tip projecting into the narrowing outlet of the interventricular foramen (fig. 7, C, and $8, \mathrm{~B})$. Its location is to the right of the primary muscular. portion of the interventricular septum, and in approximately the same parasagittal plane as the place where the sinistroventral conus ridge merges with the crest of the interventricular septum (fig. 8, B). At the same time the right tubercle of the dorsal cushion grows considerably in size and becomes merged with the interventricular septum dorsally, on the right 
side of its crescentic margin. This tubercle also bulges into the interventricular foramen at its outlet into the right ventricle.

While these changes have been going on in the region of the interventricular septum, the conus ridges have been developing rapidly. At valve level the conus ridges come into alignment with the truncus ridges in an interesting manner. Following from the distal end of the truncus toward the ventricle, the sinistro-ventral truncus ridge can be seen to spiral from the left, around toward the ventral aspect of the truncus (fig. 6, B). Caudal to the valve primordia the same spiral course is continued by the dextro-dorsal conus ridge, which starts from the ventral aspect of the upper part of the conus, and then swings around onto its right side and finally to the dorsal wall of the conus where it joins the ventricle (fig. 7, B). In like manner the spiral started by the dextrodorsal truncus ridge is continued by the sinistro-ventral conus ridge. Thus, of the approximately $180^{\circ}$ turn in the truncoconal septal system, the half above valve level is executed by the truncus ridges, and the half below valve level by the conus ridges. If one thinks of this spiral as a whole (see dotted lines in fig. $6, \mathrm{~B}$ ) the significance of the meeting of sinistro-ventral truncus ridge with dextro-dorsal conus ridge, and of dextrodorsal truncus ridge with sinistro-ventral conus ridge, will be self-evident.

The conus ridges bulge into the lumen, grow toward each other, and become fused progressively from the valve region toward the ventricle, thus forming the conus septum (figs. 7 and 8). As the conus septum grows caudad it extends toward the right border of the interventricular septum (figs. $8, \mathrm{~B}$, and 9). Toward the ventricle from the point where the conus ridges are fused to form the conus septum, they diverge sharply from each other (fig. 8, B). The dextro-dorsal ridge swings toward the orifice of the right atrioventricular canal. Its medial border reaches the right tubercle of the ventral atrioventricular canal cushion and merges with it. Its lateral border merges with the lateral cushion of the right A.-V. 
canal (fig. 7, B and C). There is thus something of the effect of the base of the dextro-dorsal conus ridge straddling the right A.-V. canal orifice. By the fusion of this basal portion of the dextro-dorsal conus ridge with the right tubercle of the ventral cushion of the A.-V. canal, the communication between

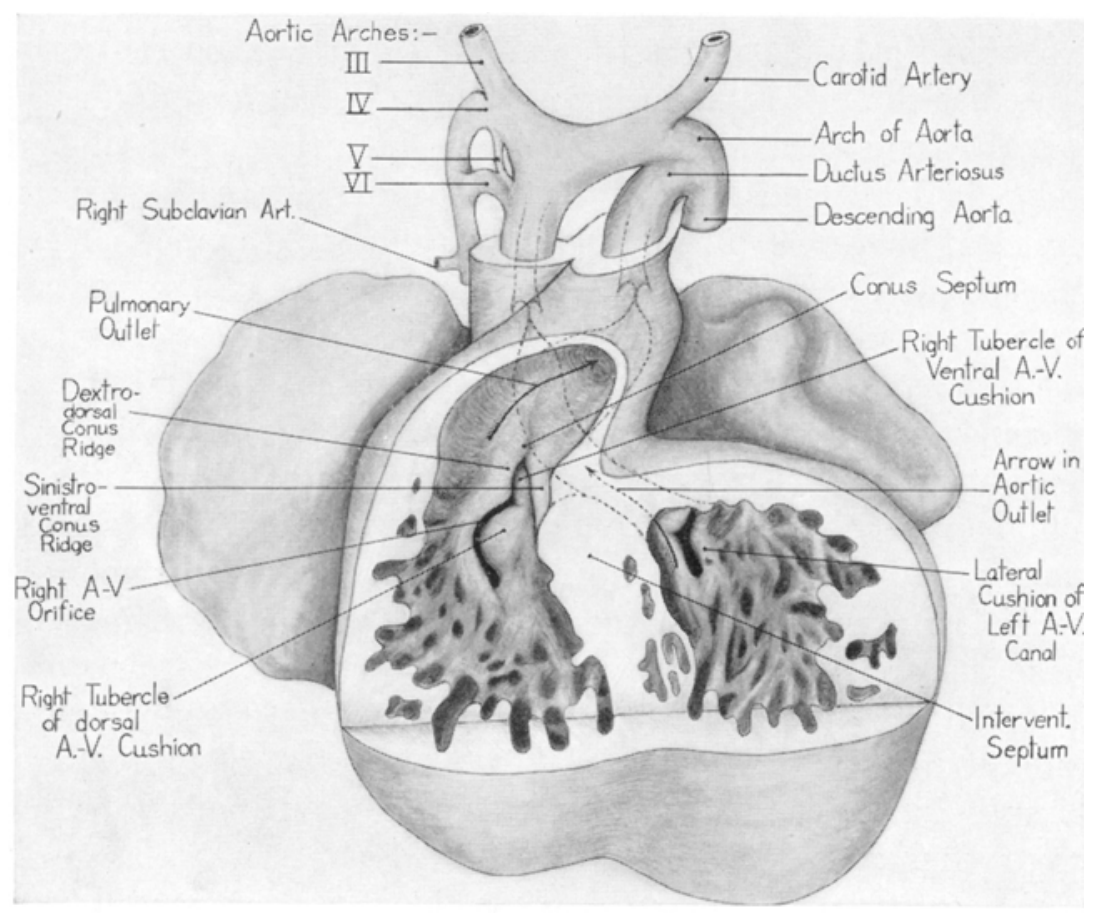

Fig. 9 Ventral view of a reconstruction of the heart of a $13-\mathrm{mm}$. embryo (Carnegie Emb. Coll. no. 841, $\times 42 \frac{1}{2}$ ). Ventral wall has been removed to show the relations of the right tubercles of the dorsal and ventral atrioventricular canal cushions with the conus ridges.

the right atrium and common ventricle, through the cephaloventral part of the atrioventricular canal is occluded. Thus is formed the part of the septal complex between the right atrium and the aortic conus of the left ventricle. It will be recalled that this part of the septum lies cephalic to the attachment, on the right, of the septal cusp of the tricuspid 
valve, and that it is known anatomically as the pars atrioventriculare of the septum membranaceum.

The sinistro-ventral conus ridge is somewhat more narrow and shorter than the dextro-dorsal conus ridge. It becomes continuous with the right border of the interventricular septum as shown in figure 8, B and figure 9. The progressive fusion of the conus ridges to form the conus septum continues to reduce the interventricular foramen. The closure is finally completed by a ring of endocardial cushion tissue contributed to by the right and left conus ridges, the endocardial cushion tissue at the crest of the interventricular septum, the right tubercle of the dorsal, and the right tubercle of the ventral atrioventricular canal cushion. Thus is formed a thick composite mass of plastic young connective tissue occluding the opening from the aortic conus into the right ventricle, and accomplishing the final step in the separation of the aortic and pulmonary channels with the establishment of the septum membranaceum. Although the fusion of all of the component parts is not complete in the 13-mm. stage, they are in such close juxtaposition that there is no doubt about the direction in which the process is progressing. The final closure of the endocardial ring ordinarily occurs in embryos of from 15 to $17 \mathrm{~mm}$. In a particularly well preserved $18-\mathrm{mm}$. embryo which was reconstructed, closure had occurred so recently that most of the component parts could still be identified. After this age the lines of demarcation between the fusing structures rapidly disappear, and the plastic endocardial cushion type of tissue by which the closure is first effected gradually becomes differentiated into the densely woven fibro-elastic connective tissue characteristic of the adult septum membranaceum.

\section{DISCUSSION}

It is clear from the foregoing study that the formation of the septal system of the truncus and conus is more complex than is usually recognized. A redefinition of the terms used in 
describing the structures involved has proved urgently necessary, both because of the discrepant usages employed by previous workers, and also because of the rapidly changing shapes and locations in which the structures themselves are found at different stages of development. It should be emphasized at the outset, however, that the mechanism of the formation of the septum membranaceum as here described in nowise invalidates the foundational work of such early investigators in the field as Born (1888, 1889) and Tandler ('12, '13); nor is it radically at variance with the careful studies of such workers as Robertson ('13), Frazer ('16 and '31), Waterston ('18), and Odgers ('38). It does, however, fill in certain gaps in the story and serves to bring into line, observations which in their early fragmentary form appeared contradictory. There do remain certain points on which I would have to take issue with previous workers. For example, as already stated, I could not subscribe to the conception of the resorption of the cono-ventricular flange, as first postulated by Keith ('06 and '09) and later accepted by Frazer ('16). Neither am I able to agree with Odgers' statement that the conus (bulbar) septum "does not contribute anything to the occlusion of the interventricular foramen or to the formation of the pars membranacea septi"' ('38, p. 258). But these are on the whole matters of detail and one's conclusions as to them depend, to a certain extent, on questions of definition. A similar situation appears to exist with regard to the fact that Odgers does not agree with Frazer's ('16) account on how much of the fused atrioventricular canal cushions go into the formation of the pars membranacea septi. It seems to me undesirable to dwell on these minor differences. It would appear much more pertinent to emphasize, as has been done in the body of this paper, major points in the complicated developmental history on which there can be agreement. It is for this reason, also, that I have attempted to utilize, in connection with drawings of my own reconstructions, some figures which capitalize and bring into line the work of previous investigators. 


\section{ACKNOWLEDGMENT}

The study was undertaken at the suggestion of Dr. Bradley M. Patten. It is a pleasure to acknowledge his many helpful suggestions in the planning of the work of his constructive criticisms in the final preparation of the text and figures.

\section{SUMMARY}

1. This paper presents a restudy, with the aid of wax plate reconstructions, of the formation of the septal systems of the truncus and conus arteriosus and their union with the primary interventricular septum.

2. The varying terms used by previous investigators have been reviewed and an attempt has been made to bring them into line with each other and, where necessary, to supplement or alter them.

3. Analysis of the partitioning processes involved shows them to be more complex than is generally realized. The following septal components must be recognized:

(a) Septum aorto-pulmonale at the level of the fourth and sixth aortic arches.

(b) Truncus ridges above the level of the semilunar valves.

(c) Intercalated valve swellings at the level of the semilunar valves.

(d) Conus ridges.

(e) The tubercles of the atrioventricular canal cushions.

4. Although arising as more or less separate structures with locally accelerated growth rates, the truncus and conus ridges become moulded into a continuous spiral septum. In this process the sinistro-ventral truncus ridge becomes aligned with the dextro-dorsal conus ridge, while the dextro-dorsal truncus ridge is aligned with the sinistro-ventral conus ridge.

5. The trunco-conal septal system is brought into line with the interventricular septum at what is destined to be the interventricular septum membranaceum. This part of the process is brought about by the apposition and fusion of the parts of a ring of endocardial cushion tissue contributed to by the 
right and left conus ridges, the endocardial cushion tissue at the crest of the interventricular septum, and the right tubercles of the atrioventricular canal cushions to form the interventricular septum membranaceum.

6. The interventricular septum membranaceum is closed between the 15- and 17-mm. stages. It is, at first, a thick composite mass of endocardial cushion tissue occluding the foramen from the aortic conus into the right ventricle. It is much later in development that this mass of endocardial cushion tissue gradually becomes differentiated into a relatively thin sheet of densely woven fibroelastic connective tissue forming the septum membranaceum in its adult form.

\section{LITERATURE CITED}

Bohm, A. A., M. Davidoff ANd G. CarL Huber 1919 Textbook of Histology. 2nd Ed., Section on microscopic technic, pp. 17-57. W. B. Saunders Co., Philadelphia.

Buchanan's Manual of An atomy 1927 Chapt. 12, vol. 2, pp. 986-1114. C. V. Mosby Co., St. Louis.

Bors, G. 1888 Über die Bildung der Klappen, Ostien und Scheidewände im Säugetierherzen. Anat. Anz., Bd. 3, S. 606-612.

1889 Beiträge zur Entwickelungsgeschichte der Säugethierherzens. Arch. Mikr. Anat., Bd. 33, S. 284-378.

DAvis, CARL L. 1927 Development of the human heart from its first appearance to the stage found in embryos of twenty paired somites. Carnegie Inst. Contrib. to Embryol., vol. 19, no. 107, pp. 245-284.

FrAZER, J. E. 1916 The formation of the pars membranacea septi. J. Anat. \& Physiol., vol. 51, pp. 19-29.

1931 A Manual of Embryology. Bailliere, Tindall and Cox, London, viii \& $486 \mathrm{pp}$.

HIs, W. 1886 a Über die Entwickelung der Form und der Abtheilungen des Herzens. Congres period. inter. de Sc. Méd. C. R. 1884. Copenhagen 1886 I. Section d'Anat., pp. 32-34.

1886 b Beiträge zur Anatomie des Menschlichen Herzens. F. C. W. Vogel, Leipzig., 20 pp., 3 pl.

HochsteTtTER, F. 1898 Über die pars membranacea septi. Wiener Klin. Wschr., Bd. 11, S. 247-248. Vortrag gehalten in d. Wiss. Aerztegesellschaft zu Innsbruck.

KeIbel, F., and F. P. Mall 1912 Manual of Human Embryology. J. B. Lippincott Co., Philadelphia, vol. I, xviii \& 548 pp.; vol. II, viii \& 1032 pp. 
Keitri, A. 1906 Malformations of the Bulbus Cordis. Studies in Pathology, Edited by William Bullock. Aberdeen University Studies, no. 21, pp. $57-74$.

1909 The Hunterian Lectures on Malformations of the Heart. Lancet, 2nd vol. for 1909, pp. 359-363, 433-435, 519-523.

MaLL, F. P. 1913 On the development of the human heart. Am. J. Anat., vol. 13, pp. 249-298.

Odaers, P. N. B. 1938 The development of the pars membranacea septi in the human heart. J. Anat. \& Physiol., vol. 72, pp. 247-259.

PAtten, B. M. 1938 Developmentai defects at the foramen ovale. Am. J. Path., vol. 14, pp. 135-161.

Patten, B. M., and T. C. Kramer 1933 The initiation of contraction in the embryonic chick heart. Am. J. Anat., vol. 53, pp. 349-375.

PatTen, B. M., ANd R. Philpott 1921 The shrinkage of embryos in the processes preparatory to sectioning. Anat. Rec., vol. 20, pp. 393-413.

RoBerTson, J. I. 1913 Comparative anatomy of the bulbus cordis, with special reference to abnormal positions of the great vessels in the human heart. J. Path., vol. 18, pp. 191-210.

TANDLer, J. 1912 The Development of the Heart. Sect. II, chapt. 18, vol. 2, in Keibel and Mall, Manual of Human Embryology, pp. 534-570.

1913 Anatomie des Herzens. In Bardeleben's Handb. der Anatomie des Menschen, Bd. 3, S. 1-292. Gustav. Fischer, Jena.

Waterston, D. 1918 The development of the heart in man. Trans. Roy. Soc. Edill., vol, 52, Part 2, pp. 257-301. 